ECCOMAS

Proceedia
COMPDYN 2021

$8^{\text {th }}$ ECCOMAS Thematic Conference on Computational Methods in Structural Dynamics and Earthquake Engineering M. Papadrakakis, M. Fragiadakis (eds.)

\title{
COMPARATIVE NON-STRUCTURAL VULNERABILITY ASSESSMENT METHODS FOR HISTORICAL RESIDENTIAL MASONRY BUILDINGS
}

\author{
Filippos Alogdianakis ${ }^{1}$, Konstantinos G. Megalooikonomou ${ }^{2}$, and Georgios S. Papavasil- \\ eiou $^{3}$ \\ ${ }^{1}$ University of Cyprus \\ 75 Kallipoleos Str., P.O. Box 20537, 1678 Nicosia, Cyprus \\ e-mail: alogdianakis.filippos@ucy.ac.cy \\ ${ }^{2}$ GFZ German Research Centre for Geosciences \\ Telegrafenberg, 14473 Potsdam, Germany \\ e-mail:kmegal@gfz-potsdam.de \\ ${ }^{3}$ University of Wolverhampton \\ Springfield Campus, Grimstone Street, Wolverhampton, WV10 0JP, United Kingdom \\ e-mail: G.Papavasileiou@wlv.ac.uk
}

\begin{abstract}
The determination of seismic risk is the foundation for risk mitigation decision-making and a key step in risk management. Large corporations and other enterprises (e.g., local governments) analyze their 'portfolio' of properties, to determine how to best allocate limited funds for structural strengthening of buildings, or other risk reduction measures such as emergency planning. When assessing the seismic vulnerability of buildings, it is essential to first establish the project objectives, before subsequently choosing the most appropriate strategy and tools necessary for building assessment and fulfillment of these objectives. It is also extremely important to understand the difference between the detailed approaches used for individual building assessment and those methods most efficient for larger scale analysis, pursued for city center assessment. While the latter results can be used as a general measure of seismic risk for different types of buildings, the actual seismic risk for any individual building may vary considerably and will depend upon its exact configuration and condition. In this study, some historical masonry buildings located in Alsace France are considered and the dynamic characteristics of these structures were estimated by the analysis of seismic noise recordings by sensors installed at each floor of the buildings under study. The estimated dynamic properties for small amplitude vibrations of these historical structures were used to derive fragility curves through vulnerability models with different level of complexity and accuracy. These fragility curves have been calculated using incremental dynamic analysis for the seismic demands generally imposed upon linear and slightly nonlinear models of single and multiple degrees of freedom, which is the case for the effects of induced seismicity. Considering the latter case of induced seismicity, the vulnerability assessment requires the expected damage to refer to non-structural components. The conclusions through comparison of the results of this study in terms of refinement of the verified structural models will prove useful for both local end-users and industrial stakeholders, with a clear perspective for a better understanding of the risk related to induced and triggered seismicity and its sound management.
\end{abstract}

Keywords: fragility curves, non-structural components, masonry, induced seismicity. 


\section{INTRODUCTION}

The determination of seismic risk is the foundation for risk mitigation decision-making, a key step in risk management. Large corporations and other enterprises (e.g., local governments) analyze their 'portfolio' of properties to best allocate limited funds for structural strengthening of buildings or other risk reduction measures such as emergency planning. When assessing the seismic vulnerability of buildings, it is essential to first establish the project objectives before choosing the most appropriate strategy and tools necessary for building the assessment and fulfilment of these objectives. It is also extremely important to understand the difference between the detailed approaches used for individual building assessment and those methods most efficient for larger-scale analysis, pursued for city center assessment. While the latter results can be used as a general measure of seismic risk for different types of buildings, the actual seismic risk for any individual building may vary considerably and will depend upon its exact configuration and condition.

In this study, some historical masonry buildings located in Alsace France, are considered, and the dynamic characteristics of these structures were estimated by the analysis of seismic noise recordings by sensors installed at each floor of the buildings under study [1],[2].

In the considered test site, the analysis of the collected exposure information indicates that traditional or historical masonry structures occur in large numbers near to the mostly rural areas close to the geothermal platforms in Alsace region in France [3]. Two general classes of structures, namely unreinforced masonry (URM) and timber-framed masonry (TFM) buildings, have been considered, and the simple performance assessment models [1],[2] have been adopted in order to carry out a preliminary vulnerability assessment for these classes of structures. The objective is to rapidly identify buildings and their non-structural components that are at greater risk in the event of an induced earthquake, and to model their non-structural fragility.

The vulnerability modelling focused on buildings constructed of masonry, which may be more susceptible to the range of ground motion expected in the event of induced seismicity in the area. The measurements have been carried out using the MPwise (Multi-Parameter Wireless Sensing System) smart device [4], which has been designed to carry out rapid measurement activities by exploiting the computing and advanced networking capacities embedded in individual units. Based on environmental, seismic noise measurements, the fundamental frequency of vibration of the inspected buildings has been estimated and used to calibrate the respective fragility curves.

In collaboration with GFZ and ES-Géothermie a three-day acquisition campaign was organized, which involved installing four sets of sensors in private houses located in villages located around the Soultz and Rittershoffen geothermal sites. The fundamental period of these structures was verified by analyzing the ambient noise measured using the MPwise sensors [4], with one sensor installed outside of the buildings and the three others installed on each floor of the houses (basement, ground floor and first floor). The sensors were installed to record the ambient noise and to draw a vulnerability mode that allows the issuing of damage forecasts (Table 1, [1],[2] ). Finally, the main geometry required as input for the simplified vulnerability models was taken through field inspection of these buildings. 


\begin{tabular}{cccccc}
\hline No & $\begin{array}{c}\text { Building } \\
\text { Type }\end{array}$ & $\begin{array}{c}\text { Building } \\
\text { Latitude }\end{array}$ & $\begin{array}{c}\text { Building } \\
\text { Longitude }\end{array}$ & $\begin{array}{c}\text { Fundamental } \\
\text { ESDOF Model } \\
\text { Period (s) }\end{array}$ & $\begin{array}{c}\text { Fundamen- } \\
\text { tal Frequen- } \\
\text { cy Sensor } \\
\text { (Hz) }\end{array}$ \\
\hline 1 & URM & 48.964946 & 7.881095 & 0.17 & 5.5 \\
\hline 2 & URM & 48.902075 & 7.874917 & 0.37 & 2.7 \\
\hline 3 & URM & 48.905270 & 7.950266 & 0.11 & 9 \\
\hline 4 & TFM & 48.914307 & 7.882233 & 0.15 & 6.7 \\
\hline 5 & URM & 48.932865 & 7.874377 & 0.32 & 3.1 \\
\hline
\end{tabular}

Table 1: Real URM and TFM buildings located near the geothermal platforms in Alsace region in France [1],[2].

\section{INCREMENTAL DYNAMIC ANALYSIS OF EQUIVALENT SINGLE DEGREE OF FREEDOM SYSTEM (ESDOF)}

The estimated dynamic properties for small-amplitude vibrations of these historical structures were used to derive simplified vulnerability models. While steel or concrete frames are mostly lumped systems with stiff diaphragms, URM buildings have distributed mass and stiffness commonly in combination with flexible diaphragms. This fact obstructs the adoption of the established methodologies to URM buildings. Specifically, the latter buildings' fundamental mode shape involves a low percentage of the total mass of the building below the $75 \%$ limit required for the good performance of ESDOF-based methods. In order to solve this issue, the simplified procedure of Vamvatsikos and Pantazopoulou (2015) [5] was adopted. In their procedure, the dynamic URM building response is represented. Global response indices are transformed to local deformation measures in closed-form seismic assessment solution both for demand and supply in the critical structural locations. The solution involves the definition of the fundamental vibration mode, approximated by 3D shape function consistent with the building's boundary conditions. Strength and deformation indices are adopted for the evaluation of the acceptance criteria. Typical local failures are estimated through a local shape of deformation while the model captures the global dynamic characteristics. The adopted method allows the automation of the necessary calculations through closed-form expressions.

In the case of TFM the walls are reinforced with timber elements, both horizontal and vertical, but also X-type diagonal braces. It is evident historically, since the Bronze Age, that the timber reinforcement into masonry walls is strongly related to seismic resistance in earthquake-prone areas. In TFM walls, there is also recent experimental and numerical evidence [6] that the diagonal braces' contribution is vital for walls' lateral behaviour in the nonlinear range due to early detachment of the masonry infill from the surrounding timber frame in the event of an earthquake. It is also observed that the diagonals in tension detach from the surrounding frame for very low horizontal displacement. Therefore, it is suggested [6] that the diagonals should contribute to the lateral behaviour only in compression and, moreover, the infill masonry walls of the timber frame should not be considered in the analytical model. Based on these considerations, a macro-model was proposed [6],[7] where its input can be easily determined since it involves only the key geometric characteristics of the timber panels and the timber strength. The latter model facilitates the seismic assessment of TFM walls resulting in a valuable tool for simplified seismic vulnerability and risk analyses [8]. Based on the resulting pushover curves produced by pushover analysis [9] of the TFM walls' macro-model, a shape-function is defined for the derivation of the ESDOF properties which is similar to the methodology already described for URM buildings [5]. 


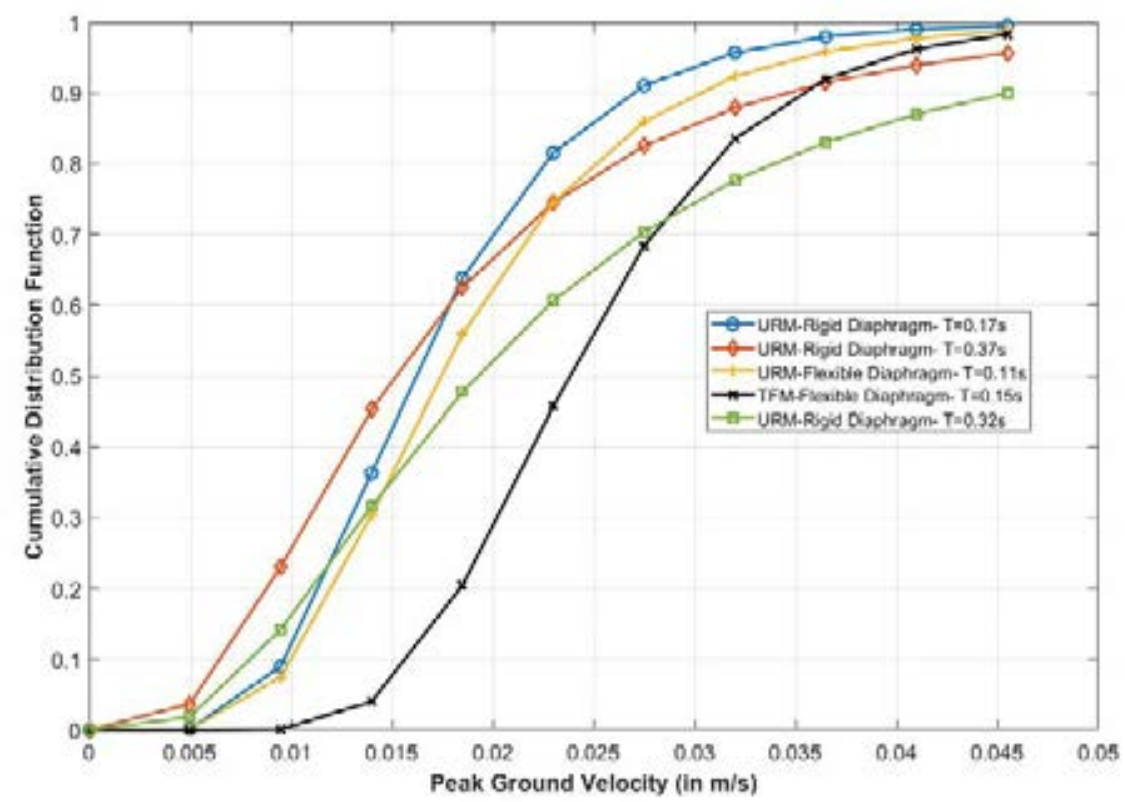

Figure 1: Proposed analytical fragility curves for first damage state (pre-yielding damage state -DS1-0.1\% drift limit for non-structural damage [14]) for Unreinforced Masonry Buildings (URM) and Timber-Framed Masonry Buildings (TFM). The buildings are located near the geothermal platforms in Alsace France and are loaded in the weak/short plan view direction of shaking. The fundamental period of these structures was verified with ambient noise measurements through applied sensors [1].

Considering these real TFM and URM building cases in Alsace France (Table 1) the corresponding fragility curves are derived in terms of Peak Ground Acceleration (PGA) with the aid of structural analysis for a gradually increasing intensity (Incremental Dynamic Analysis IDA) [10]. The latter analysis of ESDOF of the building cases under study was performed with the MATLAB [11] toolbox FEDEAS Lab [12]. The PGA values of the recordings used in the IDA with the corresponding PGV values follow the rule that for very flexible structures (structures with very high fundamental periods) the relative velocity response spectrum of the used record tends to the peak ground velocity (PGV). The induced ground motions obtained from the PEER database were employed and applied in the transverse/short/weak building plan direction [13]. As already mentioned, the fundamental periods of these structures were verified with ambient noise vibration measurements using sensors [4] located at each floor of the buildings under study (Table 1). Moreover, the main geometry required as input for the simplified vulnerability models was taken through field inspection of these buildings. The results are shown in Fig. 1. Comparing the fragility curves for URM and TFM buildings, it can be noticed that URM buildings have approximately the same range of probability of damage while the more earthquake-resistant TFM building is less fragile for low and medium intensities.

\section{INCREMENTAL DYNAMIC ANALYSIS OF THREE-DIMENSIONAL MODEL}

The above fragility curves (Fig. 1) have been developed using IDA for the seismic demands generally imposed upon linear and slightly nonlinear (serviceability limit state) models of single and multiple degrees of freedom, which is the case for the effects of induced seismicity. If considering the latter case of induced seismicity, the vulnerability assessment requires the expected damage to refer to non-structural components [14]. In this section, a comparison is provided of the results of this study in terms of refinement of the verified structural model for the No.1 building in Table 1 that will prove helpful for both local end-users 
and industrial stakeholders, with a clear perspective for a better understanding of the risk related to induced and triggered seismicity and its sound management.

\subsection{Structural modelling process}

In this work, the production of analytical fragility curves for URM buildings is demonstrated on a box-shaped unreinforced masonry structure, presented in Figure 2. Namely, this building comprises the town hall of Keffenach (URM building No.1 of Table 1) in the Alsace region in France. It can be observed in Figure 2 that the building has one storey, a roof attic and one basement. In the same Figure, the respective views of the structural model are presented.

The structural model was assessed using thick-shell elements for modelling the URM walls, thin-shell elements for the reinforced concrete floor slab, while wooden elastic frame elements with rectangular section were used for modelling the roof members. As far as it concerns material properties and the structure's dimensions, they can be found in the previous work of Megalooikonomou (2020) [2], where ESDOF analysis was performed. The ESDOF model of the URM building did not include an analytical roof model. However, it was found that the roof's bearing structure affected the period of the eigenmodes. Thus, for the analytical 3D model (Fig. 2), the roof was designed to resemble the actual building and obtain the fundamental period corresponding to $0.17 \mathrm{~s}$ (Table 1) obtained from the installed sensors.
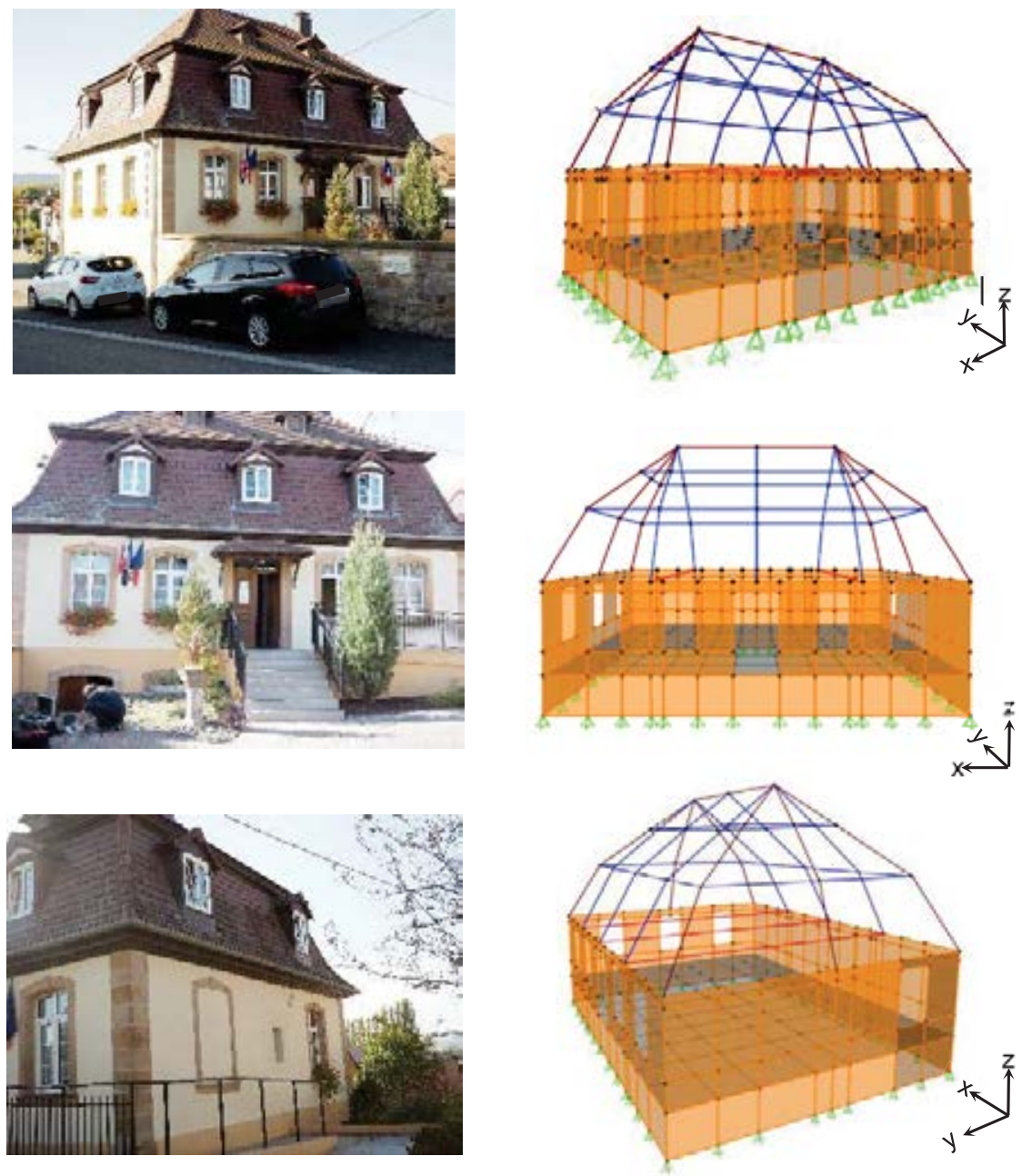

Figure 2: URM building's actual views and the generated model's respective views 


\subsection{Time history analysis}

Producing the analytical fragility curves of the 3D model requires a number of actual induced ground motion recordings, which after scaling, were used in elastic time history analysis of the 3D model. In this work, ground motion data of 9 induced earthquakes was used [13]; more information can be found in Megalooikonomou et al. (2018) [1]. The ground motion data was incrementally scaled based on its Peak Ground Acceleration to obtain different shaking levels. The levels of ground acceleration used for scaling were 10 and ranged from $0.1 \mathrm{~g}\left(9.81 \mathrm{~m} / \mathrm{s}^{2}\right)$ to $1 \mathrm{~g}$ (with increments of $0.1 \mathrm{~g}$ ). Regarding the application of the scaled ground motions, $100 \%$ of the motion was applied in the primary (weak) direction (i.e. parallel to the y-axis in Figure 2), while $30 \%$ of the same ground motion was applied simultaneously in the secondarystrong direction (i.e. parallel to the $\mathrm{x}$-axis in Figure 2).

After performing all 200 (20 recorded ground motions x 10 scale factors) elastic time history analyses, the ground motion that produced the largest displacements of the URM building is demonstrated for completeness of the present paper's results. This ground motion was recorded at the Luther Middle School station (Sparks, Oklahoma, USA) in 2011, and the earthquake had a moment magnitude of 5.68 at an epicentre distance of $54 \mathrm{~km}$ and generated a peak ground motion of $0.27 \mathrm{~g}$ [13]. Figure 3a depicts the scaled ground motion of the earthquake rendering the largest displacements of the 3D model. Moreover, the same Figure presents the time-dependent displacements for the node of the URM walls where the maximum displacement was observed for the weak building direction of applied ground motion (Figure 3b) and the same in the strong building direction (Figure $3 \mathrm{c}$ ).
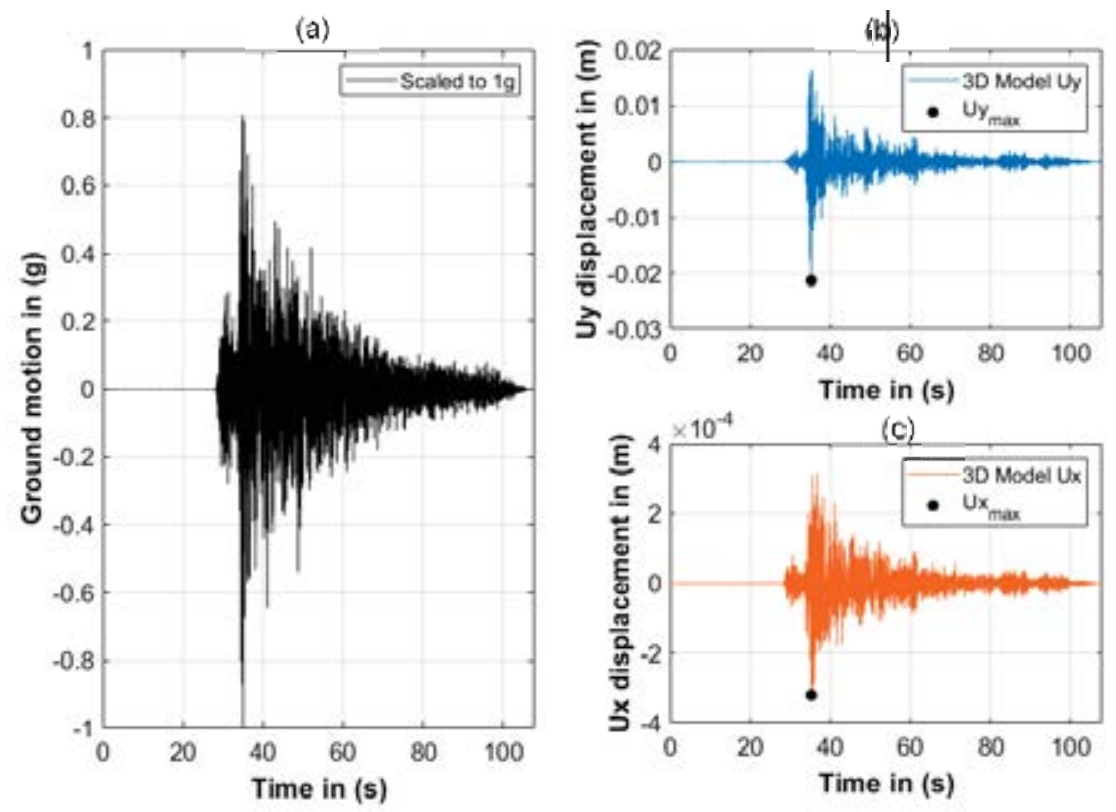

Figure 3: (a) Ground motion of earthquake producing maximum displacements; (b) node displacement for weak building direction (y-direction in Figure 2) and (c) node displacement for strong building direction (xdirection in Figure 2).

\subsection{Analysis results}

The results of the elastic time history analyses of the 20 ground motions and the considered scale factors for the 3D and ESDOF models were used to fit log-normal distributions for each model. Figure 4a presents the probability density functions of the 3D model and ESDOF. His- 
tograms of the natural logarithm of maximum drift comprise the analysis actual results that allowed normal distributions to be fitted for both 3D and ESDOF models (Figure 4a). The fits were used to estimate the fragility curves for the different levels of Peak Ground Velocity (PGV) depicted in Figure 4b [see also Figure 1 (URM, T=0.17s)]. It is evident from Figure 4b that the $3 \mathrm{D}$ detailed analytical model results to a more vulnerable to non-structural damage historical masonry building.

(a)

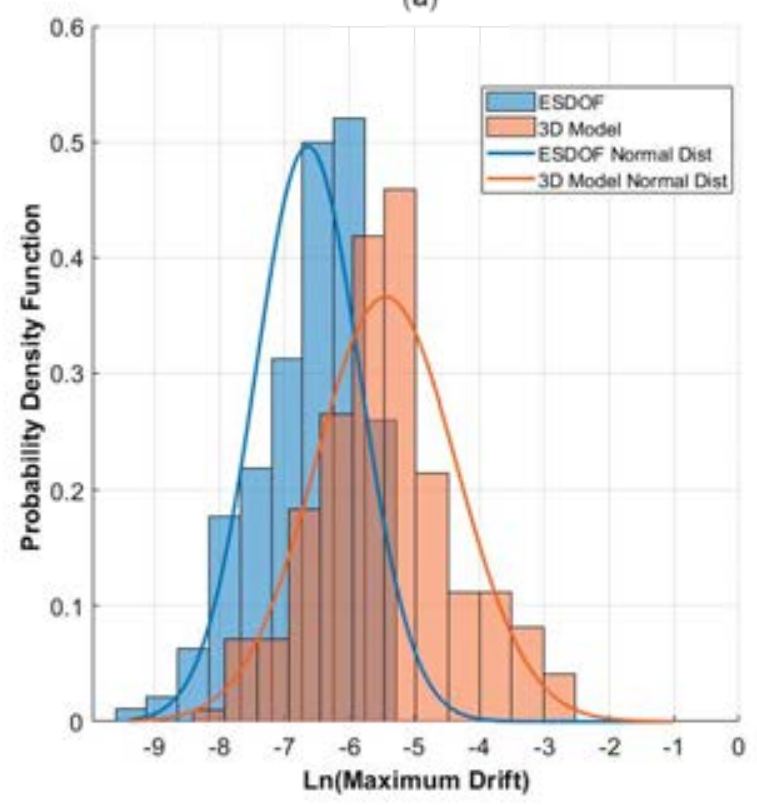

(b)

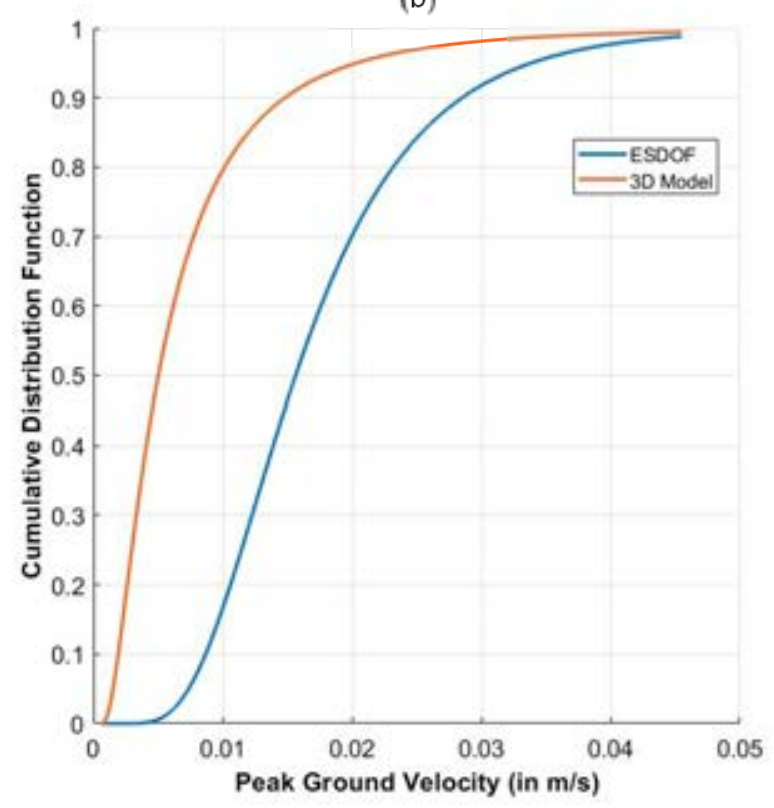

Figure 4: Analysis results for ESDOF and 3D model: (a) Relative frequency and probability density function of the natural logarithm of the maximum drift at height $3.81 \mathrm{~m}$ and (b) Fragility curves $-\mathrm{PGV}$ in $(\mathrm{m} / \mathrm{s})$.

\section{CONCLUSIONS}

- The estimated dynamic properties for small amplitude vibrations of the historical structures near the geothermal platforms in Alsace, France considered in this work were used to derive simplified vulnerability models that were compared with a detailed 3D model for one of these masonry buildings under study.

- Moreover, Eurocode 8 defines the interstorey drift limit of a building for non-structural damage by looking at its displacement-sensitive non-structural components at the serviceability limit state. Adopting these limits and the developed vulnerability models, new non-structural fragility curves for typical historical masonry building types dominant in the region under study are proposed.

- The fragility curves have been calculated using incremental dynamic analysis for the seismic demands generally imposed upon linear and slightly nonlinear models of single and multiple degrees of freedom, which is the case for the effects of induced seismicity.

- A comparison is provided of the results of this study in terms of refinement of the verified structural model. It is evident that using simplified vulnerability models compared to detailed 3D structural models may lead to a considerable error regarding the probability of non-structural damage due to induced seismic events.

- These results will prove useful for both local end-users and industrial stakeholders, with a clear perspective for a better understanding of the risk related to induced and triggered seismicity and its sound management. 


\section{REFERENCES}

[1] Megalooikonomou KG, Parolai S, Pittore M. (2018) Toward performance-driven seismic risk monitoring for geothermal platforms: development of ad hoc fragility curves, Geothermal Energy, 6(1):8, doi: 10.1186/s40517-018-0094-3

[2] Megalooikonomou KG. (2020) Contribution of seismic noise recordings to the nonstructural vulnerability assessment. In Proceedings of EURODYN 2020 XI International Conference on Structural Dynamics. Athens Greece 22-24 July 2020 https://doi.org/10.47964/1120.9395.18340

[3] Pittore M, Haas M and Megalooikonomou KG (2018) Risk-Oriented, Bottom-Up Modeling of Building Portfolios with Faceted Taxonomies. Front. Built Environ. 4:41. doi: 10.3389/fbuil.2018.00041

[4] Boxberger T, Fleming K, Pittore M, Parolai S, Pilz M, Mikulla S (2017) The MultiParameter Wireless Sensing System (MPwise): its description and application to earthquake risk mitigation. Sensors 17(10):2400. doi:10.3390/s17102400

[5] Vamvatsikos D., Pantazopoulou S. J. (2015) Development of a simplified mechanical model to estimate the seismic vulnerability of heritage unreinforced masonry buildings. Journal of Earthquake Engineering, Taylor \& Fran, 20(2): 298-325. doi:10.1080/13632469.2015.1060583.

[6] Kouris LAS., Kappos AJ (2014) A practice - oriented model for pushover analysis of a class of timber-framed masonry buildings, Engineering Structures Journal, Elsevier, 75: 489-506. doi: 10.1016/j.engstruct.2014.06.012.

[7] Kouris LAS., Kappos AJ (2012) Detailed and simplified nonlinear models for timberframed masonry structures, Journal of Cultural Heritage, Elsevier, 13 (1): 47-58. doi: 10.1016/j.culher.2011.05.009.

[8] Kouris L.A.S., Kappos A.J. (2015) Fragility Curves and Loss Estimation for Traditional Timber-Framed Masonry Buildings in Lefkas, Greece. In: Psycharis I., Pantazopoulou S., Papadrakakis M. (eds) Seismic Assessment, Behavior and Retrofit of Heritage Buildings and Monuments. Computational Methods in Applied Sciences, vol 37. Springer, Cham. doi: 10.1007/978-3-319-16130-3_8.

[9] Antoniou, S, Pinho, R (2004) Development and verification of a displacement-based adaptive pushover procedure, Journal of Earthquake Engineering 8(5), 643-661. doi: 10.1080/13632460409350504.

[10] Vamvatsikos D., Cornell C.A. (2002). Incremental Dynamic Analysis. Earthquake Engineering and Structural Dynamics, 31(3): 491-514. doi: 10.1002/eqe.141.

[11] Mathworks. (2017). MATLAB: User's Guide (r2017a).

[12] Filippou F.C., Constantinides M., (2004) FEDEAS Lab - Getting Started Guide and Simulation Examples, NEESgrid Report 2004-22 and SEMM Report 2004-05.

[13] PEER-NGA-East Database (2017). Pacific Earthquake Engineering Research Center, University of California, Berkeley, CA, (http://peer.berkeley.edu/ngaeast/).

[14] CEN (2004) Eurocode 8: design of structures for earthquake resistance - Part I: general rules, seismic actions and rules for buildings. European Committee for Standardization (CEN). Brussels, Belgium. 